Poles in exile than it was in Poland before the War, so that there is urgent need of the developments which are contemplated.

Something of what is happening in Poland now may be imagined by reading between the lines of the extract from a secret report on the condition of the Polish children which this journal publishes. At all ages the theoretical rations of Polish children are half the theoretical normal calorie value, while those of Nazi children are well above this norm. In practice, the writer of this report states, the quantity and quality of the food fluctuate; sometimes it is reduced to nil. In the Rodom district, for example, the children of the landworkers do not get any ration cards at all. Almost everywhere the distribution of milk to children under three has been suspended. The writer concludes that the rations show a deficiency of 90 per cent of fats, 80 per cent of albumins and 50-60 per cent of carbohydrates. It is not surprising that infectious diseases and "a frightening mortality", with a high percentage of tuberculosis, which is increasing, and of heart weakness are evident among Polish children. These conditions are, as recent articles in the British Medical Journal and The Lancet and diseussions in the Houses of Lords and Commons have shown, reproduced in most of the occupied countries. It is easy to exaggerate them; but we should not commit the graver error of underestimating their consequences. The agricultural basis of European rehabilitation is clearly recognized, and Polish veterinarians have for long been co-operating with British veterinarians in the reconstruction of Polish veterinary medicine. An article on this, and others on the improvement of Polish milk hygiene and on the eradication of tuberculosis from Polish cattle, 25-50 per cent of which are, Dr. Mglej tells us, tuberculous, indicate that this aspect of the future is not being neglected.

\section{Classification in Biology}

THE question is often asked by students as to which is the 'right' classification of a group of animals. Mr. K. H. Chapman, lecturer in zoology, Rhodes University College, Grahamstown, South Africa, directs attention to certain ideas that must be kept in mind when considering schemes of classification from this point of view in a communication to the Editors which is summarized below. Although such conceptions have been put forward before, there persists so much misconception about the nature and purpose of systematies in biology, not only among students but also among biologists themselves, that it is necessary to re-emphasize these points. It is probable that no classification is right or definitive because there is no real classificatory system outside ourselves that it is only necessary for us to discover. In most groups it is obvious that we can only deal with survivors; and even where fossils do exist, they are unselected members of the group from this point of view. Thus it follows that natural classification is an unfortunate term. Living animals do not fall into true and equivalent groups even though we arbitrarily place them in such, and consequently we can only regard classification as a convenient tool with which to deal with a large mass of material, and it does not have a natural existence of itself. It is only necessary to compare the species, genera and other groups of insects with the similarly named categories in other phyla to realize their nonequivalence. The species, whatever it may be, also must be regarded as a dynamic and not a static unit, and any living group may, in the course of time, become something different. The question of polyphylletic origins also arises; for example, W. A. Herdman suggested that the compound ascidians are an assemblage of groups evolved from different groups of the simple ascidians which had independently assumed the colonial habit of growth. Any classification is to be regarded as an expression of a scale of values which indicates, in the opinion of its proposer, the relative nearness or farness of two or more groups with respect to one another.

\section{The British Bryological Society}

Few associations of naturalists have been originated by advertisement, but such was the genesis of the Moss Exchange Club. The Rev. C. H. Waddell first advertised in Science Gossip in December 1895 and, from the twenty-three favourable replies, founded the Club in the following year, when 2,077 specimens were distributed. It remained an association depending very largely on postal contact until 1922, when the need for closer personal association in field meetings led to the formation of the British Bryological Society. Miss Eleonora Armitage has collated the annual reports of both Club and Society into a short pamphlet (Miss Armitage, Dadnor, Ross). She was president at the Society's last meeting in 1939, and this review should serve the purpose of sustaining the collective interests of bryologists until more stable times allow a resumption of their activities. Several census lists of British bryophytes have been published, from the York Catalogue, compiled by $J$. A. Wheldon in 1889 , to the latest taxonomic indexes for mosses, compiled by J. B. Duncan in 1926, and for hepatics, by A. Wilson in 1930. The taxonomy of mosses and liverworts is now largely established, but many bryological matters still require elucidation. Perhaps the post-war period will provide opportunities for detailed ecological studies - the relation of a moss or liverwort to its substrate, its reactions with other plants, and particularly of its unique physiology, which allows a special phenology of reproduction not possessed by any other kind of plant.

\section{Work of the League of Nations}

THE report on the work of the League of Nations during 1942-43, submitted by the Acting SecretaryGeneral, in addition to an introductory section giving a useful survey of proposals for future world organization, contains chapters on economic, financial and transit questions, on questions of a social and humanitarian character, on questions of a legal and administrative character and on the Library of the League. The work of the League on the first group of questions is reflected chiefly in a series of reports which have already been noticed; but in regard to the second group; the report affords strong evidence that whatever views may be held as to the continuance of the League as a co-ordinating machinery in political affairs, its technical organizations should be retained as part of the functional apparatus set up in any future world organization.

The Health Section has concentrated its attention during the year on the present food scarcity, and on malnutrition and the danger of epidemic outbreaks in Europe. A comprehensive study of the trend of morbidity and mortality of European countries in relation to food shortage is shortly to 
appear in the Bulletin of the Health Organisation. The Organisation has also been requested to determine which food elements are most acutely lacking in the present dietary of enemy-occupied countries, so that foods prepared by the Allied Food Relief Organization should, in the form of adequate complement rations, compensate present deficiencies. Information on the health situation in Europe was summarized in a series of notes on the prevalence, trend and probable course of typhus fever, cerebro-spinal meningitis, enteric fever, scarlet fever, smallpox, poliomyelitis, etc., and typhus fever was also the subject of a special study. The Singapore Bureau functioned until less than a week before the occupation of Singapore by the Japanese in January 1942. The activities of the Health Information Service have been maintained, and a study on the significance of names of communicable diseases in various languages was amplified and extended to form the basis of a comprehensive glossary in twenty-four languages of the communicable diseases. Research has continued on several subjects on the agenda of the Permanent Commission on Biological Standardization, including the nature of the toxins produced by the tetanus germ and by Bacillus perfringens, one of the agents of gas gangrene.

In regard to the Control of the Drug Traffic, international supervision has been impaired by the deterioration of communications, and difficulties in obtaining the necessary supplies have in some South American countries led to plans to produce raw opium and to manufacture drugs. The report directs attention to the danger that an excess of manufacture over legitimate needs may follow, and to the importance of taking, as soon as possible, all necessary steps to restore the full measures of control as they existed before the War. Work has already commenced on a post-war planning programme in this field, which includes a study and review of present national and international systems of control, with the view of suggesting improvements, and a study has been made of the legal position of drug addicts and current methods for treatment of addiction. The collections of the Library comprised about 318,200 volumes at the end of 1942, and in view of the exceptional facilities for work which the documentary material available will offer after the War, the secretariat is studying the means by which a gradual return to normal conditions may be effected.

\section{Smithsonian Institution : Annual Report}

THE report of the Secretary of the Smithsonian Institution for the year ending June 30, 1943, includes the report of the secretary and the financial report of the executive committee of the Board of Regents, together with the usual reports of the United States National Museum, the National Gallery of Art, the National Collection of Fine Art, the Freer Gallery of Art, the Bureau of American Ethnology, the International Fxchange Service, the Astrophysical Observatory and on the Library. The secretary's report points out that all personnel and facilities of the Institution and its branches were made available and extensively used in the prosecution of the War, although the normal activities were kept alive to the extent of continuing observations the cessation of which would leave permanent gaps in records essential for future investigations and of maintaining and caring for the national collections. All other research and exploratory projects not required for the orderly resumption of cultural activities after the War have been suspended, except those activities relating to closer cultural co-operation with the other American republics. Much of the Institution's contribution to the war effort is of an indirect nature. More than a thousand recorded inquiries had been answered up to the close of the fiscal year, and a list of selected examples tabulated by the War Com. mittee shows not only the wide range of these questions but also the extent to which modern total war depends on scientific knowledge.

War research projects have also been concerned with many different branches of science, including anthropology, biology, geology, physics and meteorology, and these projects occupied almost the whole time of the instrument and mechanical shops of the Astrophysical Observatory, the Division of Radiation and Organisms and the Division of Engineering, as well as of numerous individual members of the scientific staff. With regard to inter-American co-operation, the report refers to the organization of an Inter-American Society of Geography and Anthropology, with membership open to scientific workers anywhere in the hemisphere. More than 700 members have already been enrolled. The first part of a check list of the coleopterous insects of Mexico, Central America, the West Indies and South America is now in the Press as a bulletin of the National Museum. A prediction of the march of solar variation during 1939-45 based on periodicities revealed by the solar-constant values published in vol. 6 of the Annals of the Astrophysical Observatory shows that the years $1940-47$ will be the most important years to study the sun's variations since the early twenties, and for this reason every effort has been made to keep the three field observatories in Chile, California and New Mexico in operation. With regard to the international exchanges, the report records that the Office of Censorship lifted in January 1943 the ban imposed in April 1942 on sending abroad the Congressional Record and the Federal Register.

\section{Office Organization in Engineering Works}

A BOokLET issued by the British Standards Institution, "Office Organisation and Practice" (B.S.1100; Part 10; 1943), states in some detail the underlying principles of good office management and clerical organization, and gives practical guidance as to the installation of a system and the technique of office and clerical organization. It is addressed primarily to engineering firms of 250-1,000 employees with offices of 20-100 clerks, but the large amount of basic information on office practice condensed and set out simply in this booklet should be equally valuable to smaller firms in all branches of industry. Sections are included on the planning of systems; the design and use of forms ; the use and selection of machines and other devices, with an appendix listing suppliers; accommodation, lay-out, lighting and heating requirements of offices; personnel organization, including the grading of jobs and standards of performance and incentives ; training, selection, coordination and control of staff, and methods of inspection of work. Typing is dealt with in a separate section including both selection and training and the pool system, while a further section deals with communications, both inward and outward mail, the use of telephones and messengers. There is a short 